\title{
PERSISTENT CONDUCTION DEFECTS FOLLOWING DIPHTHERIA
}

\author{
BY \\ C. BRUCE PERRY \\ From the Department of Medicine, University of Bristol \\ Received December 29, 1938
}

Whether diphtheria commonly causes any permanent cardiac damage has long been the subject of discussion; but it is generally accepted that the persistence of electrocardiographic changes of any serious significance is extremely rare (Alstead, 1933 ; Beer, 1936 ; Begg, 1937 ; Hoskin, 1926 ; Jones and White, 1927 ; and Thompson, Golden, and White, 1937). It is not uncommon for complete heart block and bundle branch block to develop during the course of severe diphtheria, usually during the second week (Alstead, 1932 ; Begg, 1937 ; Franck, 1935 ; Place, 1932 ; and Schwensen, 1922). The mortality amongst cases showing these changes is high, but if the patient survives there is usually a complete cardiac recovery.

Parkinson (1915) has described the case of a man, aged 22, who, on the twenty-second day of a severe attack of diphtheria, developed complete heart block. This lasted for eleven days, when auricular fibrillation supervened. At first the ventricular rate was slow ( 50 per minute), but later increased to 100 110 per minute. The fibrillation persisted for at least six months. Sprague and White (1927) have reported the case of a woman, aged 22, with complete heart block dating from diphtheria 19 years before. Read (1929) described a woman, aged 48, with complete heart block which, it was believed, dated from an attack of diphtheria at the age of 6 ; and Chamberlain and Alstead (1931) have published the details of a woman, aged 28 , with complete heart block following diphtheria 18 years before. Butler and Levine (1930), investigating twenty cases with heart block of obscure origin, found a history of diphtheria in ten, whereas of 600 surgical cases studied as controls the incidence of a history of diphtheria was only six per cent. As a result of these observations it was suggested that diphtheria may predispose to the development of heart block in later life. However, Thompson, Golden, and White (1937) investigated ninety-one patients who had severe diphtheria 15 to 20 years previously, but found no evidence that diphtheria predisposed to the subsequent development of conduction defects.

In view of the rarity of persistent defects in cardiac conduction after recovery from diphtheria, the three following cases appear worthy of record. In two there was persistent complete heart block and in one persistent bundle branch block. 


\section{Two Cases of Complete Heart Block.}

Case 1. J. H., female, aged 14. Reported previously (Perry, 1931).

On November 13, 1929, this patient was admitted to Ham Green Fever Hospital on the third day of a severe attack of diphtheria. There was extensive membrane and a "bull neck." She was given 40,000 units of anti-toxin. On November 19 the pulse dropped to 70 and on December 10 to 54-60 per minute. From this time until she was discharged on February 6, 1930, the pulse rate varied from 48-64. Palatal palsy necessitated nasal feeding for a time. Complete heart block was first demonstrated on September 30,1930, and since that time there has been no change in the cardiac rhythm or in the physical signs.

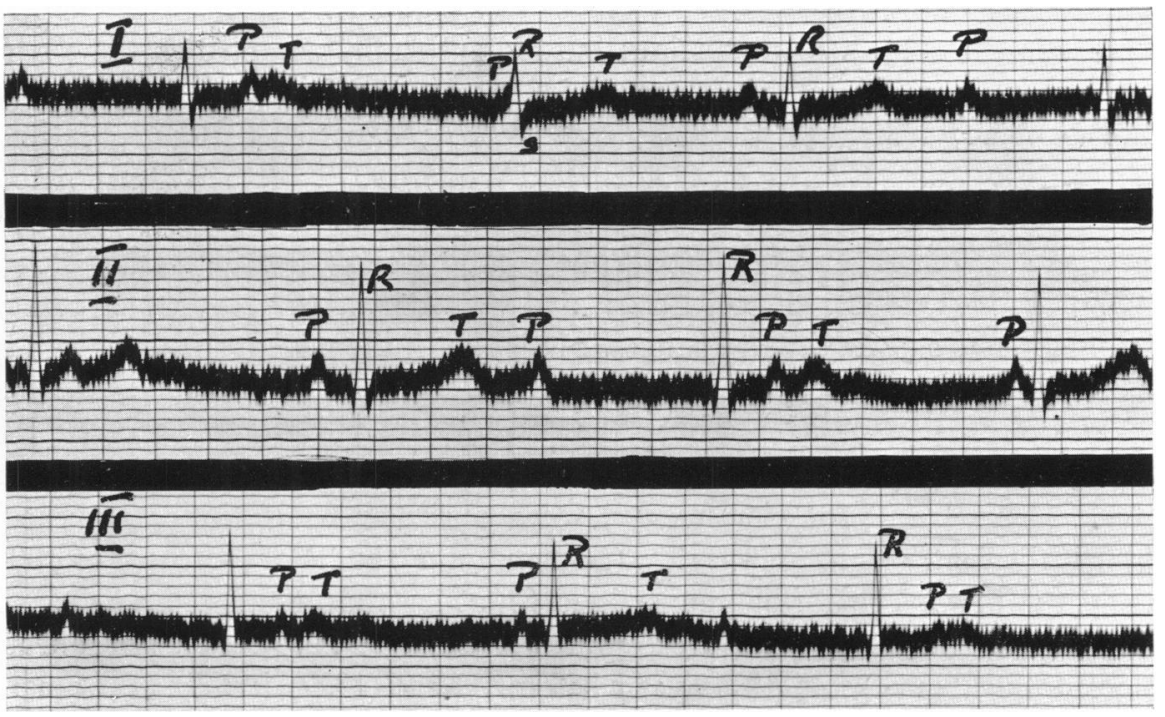

FIG. 1.-Electrocardiogram of Case 1.

She attends school normally, but is not allowed to take part in games or drill. There have been no symptoms referable to the cardiac lesion. The apex beat is diffuse and forcible in and beyond the mid-clavicular line. The heart sounds vary in intensity from beat to beat and there is an inconstant diastolic sound. There are no murmurs. The blood pressure is 115/70. An X-ray shows a heart which is generally enlarged, particularly the left ventricle, with a cardio-thoracic ratio of 65 . An electrocardiogram shows complete heart block with a ventricular rate of 50 .

Case 2. J. T., female, aged 13.

This patient was admitted to Ham Green Hospital on June 27, 1931, with very severe diphtheria which had commenced on June 23. There was extensive 
membrane and œdema of the neck. She received 46,000 units of anti-toxin intravenously with five ounces of 20 per cent. glucose. At the end of the second week she showed the cardiac vomiting syndrome, which was treated by intravenous glucose and finally stopped. On July 8 palatal paralysis developed, followed on July 31 by strabismus and ptosis. After the second week the pulse remained between 80 and 90 until September 2, when it fell to 60. At the same time there was vomiting, pyrexia, and slight enlargement of the neck glands. The patient was discharged from hospital on September 18. On October 13 an electrocardiogram showed complete heart block. At that time there was some weakness of the leg muscles.

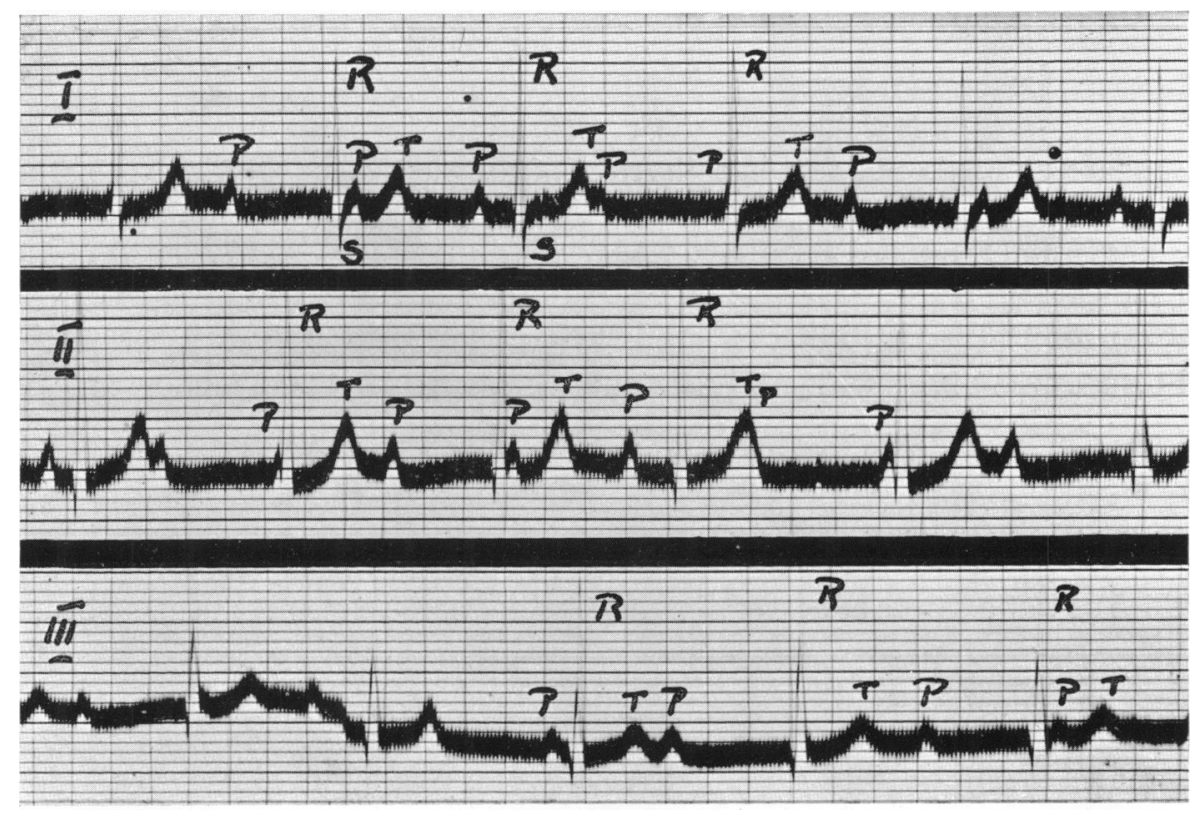

FIG. 2.-Electrocardiogram of Case 2.

By April 1932 she appeared to be perfectly well, but the cardiac condition was unchanged and has remained so ever since. She attends school normally, but is not allowed to take part in games or drill. The apex beat is diffuse and forcible beyond the mid-clavicular line. The heart sounds vary in intensity from beat to beat and there is an inconstant mid-diastolic sound. There is a loud apical systolic murmur. The blood pressure is 120/65. An X-ray shows an enlarged left ventricle with a cardio-thoracic ratio of 56, and a prominent pulmonary artery. The electrocardiogram shows complete heart block with a ventricular rate of 59 .

\section{Comment.}

In these two cases of persistent heart block the conduction defect dates from an attack of severe diphtheria. In the first the heart block developed at the 
usual time, during the second week of the illness. The very late development of the conduction defect in the second, associated with an apparent relapse or fresh infection forty days after the onset of the disease, suggests that the heart block may possibly be due to an attack of rheumatic carditis, and the apical systolic murmur may be considered further evidence of this. However, no other manifestations of acute rheumatism were noted and there has been no rheumatic episode since the heart block was discovered, such as might have been expected had this been rheumatic in origin. Alstead (1932) found that in the acute stage of diphtheria complete heart block might easily pass unnoticed without electrocardiographic studies, since the ventricular rate may be as high as 100 per minute. In view of this it is possible that the heart block in the second case developed before September 2, but this seems rather unlikely since there was a definite setback at the time with pyrexia and vomiting, quite apart from the fall in pulse rate.

A feature of both cases is the comparatively rapid ventricular rate. A similar rate has been noted in children with complete heart block due to rheumatic heart disease (Perry, 1931). It is interesting to note that in the cases of diphtheritic heart block described by Chamberlain and Alstead (1931) and by Read (1929) the pulse rates were both over 40 at the age of 28 and 48 respectively. It is curious that these two cases and the three reported by Sprague and White, by Chamberlain and Alstead, and by Read are all females.

\section{One Case of Bundle Branch Block.}

Case 3. G. H., male, aged 16.

This boy was admitted to Ham Green Hospital on January 10, 1931, on the third day of a severe attack of diphtheria with extensive membrane and œdema

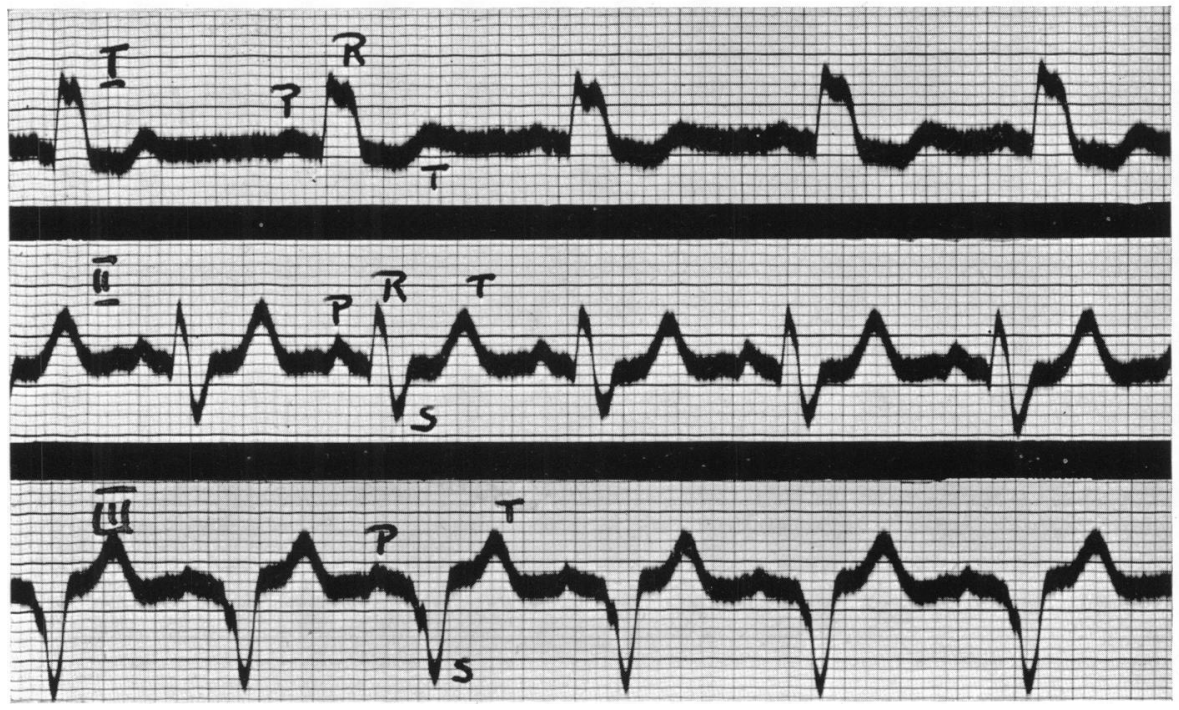

FIG. 3.-Electrocardiogram of Case 3 
of the neck. He received 40,000 units of anti-toxin intravenously. On January 18 he developed palatal paralysis. On February 3 he vomited, the heart was dilated, and the liver was enlarged and tender. He was treated by intravenous glucose and improved. The heart remained dilated and the pulse rate 104-112 until April 29, when he was discharged from hospital at the parents' request.

On March 16, 1932, he was quite well and had no symptoms. The apex beat and heart sounds were normal and there were no murmurs. An electrocardiogram showed bundle branch block of the common (left) variety; this has been present whenever he has been examined since. At times a soft apical systolic murmur has been noted, but this is not constant. The blood pressure was $110 / 65$. An X-ray showed a small vertical heart with a cardio-thoracic ratio of 45 . He attended school normally, but was not allowed to play games or to do drill. He is now (1938) working quite successfully.

\section{Comment}

This last patient obviously suffered from very severe cardiac damage during the attack of diphtheria, and it would appear justifiable to attribute the persistent bundle branch block to this, since there has been no suggestion of any rheumatic infection before or after. This would seem to be the first record of a case of bundle branch block due to diphtheria that has persisted with the recovery of the patient.

\section{SUMMARY}

A description has been given of three children who recovered from attacks of diphtheria with persistent conduction defects. In two this took the form of complete heart block and in the third of bundle branch block. In all three the lesion seems to have developed at the time of their diphtheria or shortly after, and in all it has persisted for some years.

I am greatly indebted to Dr. B. A. Peters for very kindly supplying the information about these cases while they were in the Fever Hospital.

\section{REFERENCES}

Alstead, S. (1932). Quart. J. Med., 25, 277.

(1933). Lancet, 1, 413.

Beer, A. (1936). Jhrb. Kinderheilk., 148, 152.

Begg. N. D. (1937). Lancet, 1, 857. 
Butler, S., and Levine, S. A. (1930). Amer. Heart J., 5, 592.

Chamberland, E. N., and Alstead, S. (1931). Lancet, 1, 970.

Franck, H. (1935). Dtsch. Med. Wschr., 61, 1,025.

Hoskin, J. (1926). Lancet, 2, 1,141.

Jones, T. D., and White, P. D. (1927). Amer. Heart J., 3, 190.

Parkinson, J. (1915). Heart, 6, 13.

Perry, C. B. (1931). Proc. Royal Soc. Med., 24, 100.

Place, E. H. (1932). New Engl. J. Med., 207, 864.

Read, J. M. (1929). J. Amer. Med. Ass., 93, 1,125.

Schwensen, C. (1922). Journ. infect. Dis., 30, 279.

Sprague, H. B., and White, P. D. (1927). Med. Clin. N. Amer., 10, 1,235.

Thompson, W. P., Golden, S. E., and White, P. D. (1937). Amer. Heart J., 13, 534. 